\title{
A Case report on Interhemispheric Epidermoid Tumor
}

Joarder MA ${ }^{1}$, Karim B ${ }^{2}$, Kamal $\mathrm{T}^{3}$, Suzon SI ${ }^{4}$, Nahid Akhter $\mathrm{N}^{5}$, Islam K ${ }^{6}$, Hossain MZ ${ }^{7}$, Mollik $\mathrm{A}^{8}$, Sultana $\mathrm{S}^{9}$, Shankar DRK ${ }^{10}$, Chandy $\mathrm{M}^{11}$

\begin{abstract}
A 30 year old man admitted with the complaints of generalized convulsions, headache and amnesia. The radiological and neuro-pathological findings were interhemispheric epidermoid tumor, which is a rare location. The tumor was removed completely. The diagnosis and management of epidermoid tumors are discussed by reviewing the literature.
\end{abstract}

\section{Introduction}

Intracranial epidermoid tumors, which are inclusion tumors of the central nervous system, are congenital neoplasm's that grow through desquamation of keratin, cholesterol and cellular debris. They constitute 0.5 to 1.8 per cent of all brain tumors. ${ }^{14}$ The expansion usually conforms to available subarachnoid spaces. 2,14 The most common intracranial locations are the parachiasmal and cerebellopontine angle regions. ${ }^{1,4}$ and the most common single symptom is seizures. ${ }^{7}$ The goal of surgery is total removal. ${ }^{15}$ These are curable tumors and the only real chance for this cure is the first operation. We report the case of a patient with epidermoid tumor in the longitudinal interhemispheric fissure who presented with convulsions.

\section{Case Report}

A 30 year old man was admitted to Department of Neurosurgery with the complaint of generalized convulsion, headache and amnesia. He had history of two episodes of generalized convulsion: one year ago, the other six months ago. He had been suffering from headache and amnesia for the last two months. He had no history of unconsciousness. Neurological examination was normal except for bilateral papilledema.

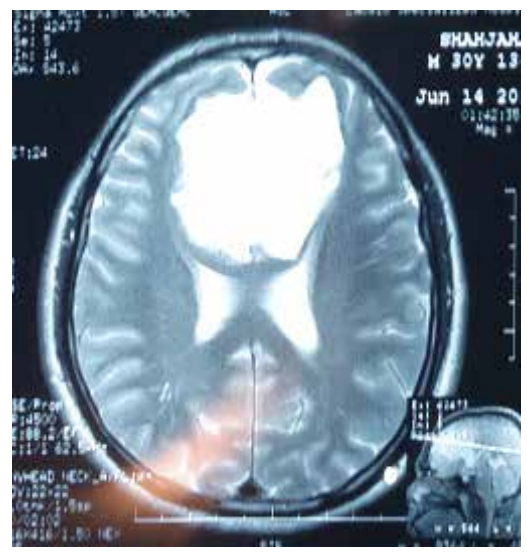

Fig. 1: On magnetic resonance imaging (MRI). The tumour was hypointense on Tl-weighted sequence and hyperintense on $\mathrm{T} 2$-weighted sequence.

1.Specialist, Department of Neurosurgery, Apollo Hospitals Dhaka 2. Registrar, Department of Neurosurgery, Apollo Hospitals Dhaka 3-4. Clinical associate. Department of Neurosurgery, Apollo Hospitals Dhaka 5. SMO, Department of Neurosurgery, Apollo Hospitals Dhaka 6-9. RMO, Department of Neurosurgery, Apollo Hospitals Dhaka 10. Senior Consultant, Department of Neurosurgery, Apollo Hospitals Dhaka 11. Senior Consultant and coordinator, Department of Neurosurgery, Apollo Hospitals Dhaka. 

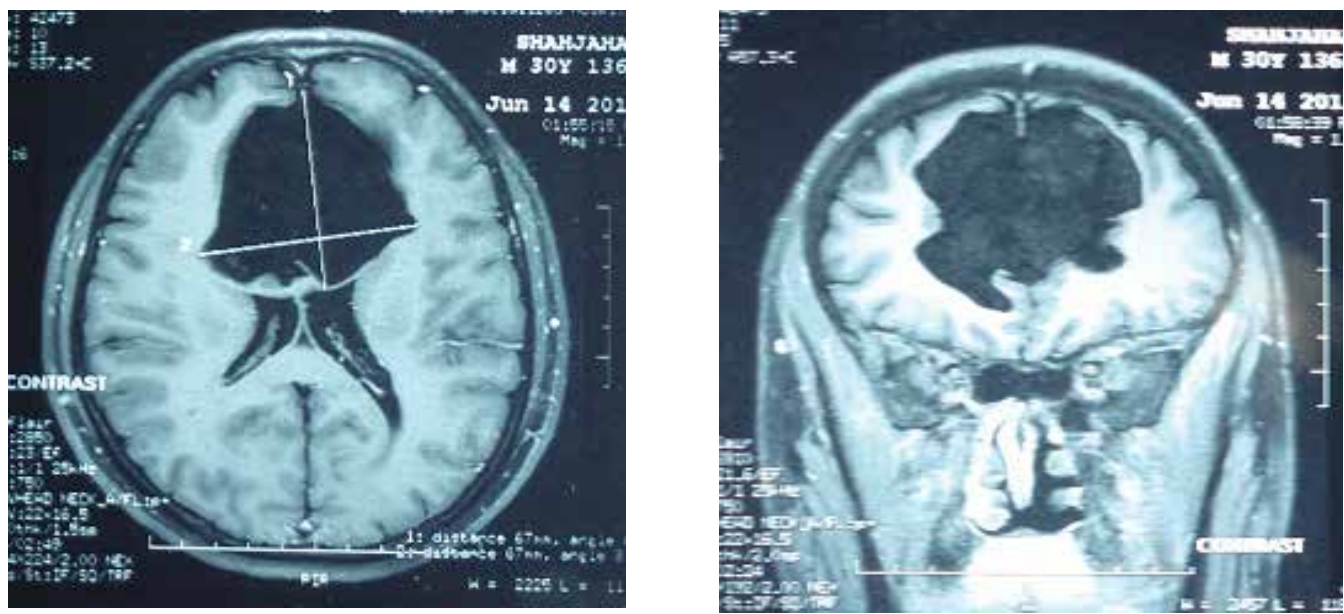

Fig 2: Contrast enhanced $\mathrm{Tl}$ - weighted images demonstrate a hypointense mass in the interhemispheric fissure.

A bilateral frontal craniotomy was performed. The dura mater was opened and the tumor, which had a nodular, glistening white appearance, was removed completely along with the capsule. Steroids and antiepileptics were given perioperatively. There was no complication in the early postoperative period. $\mathrm{He}$ was

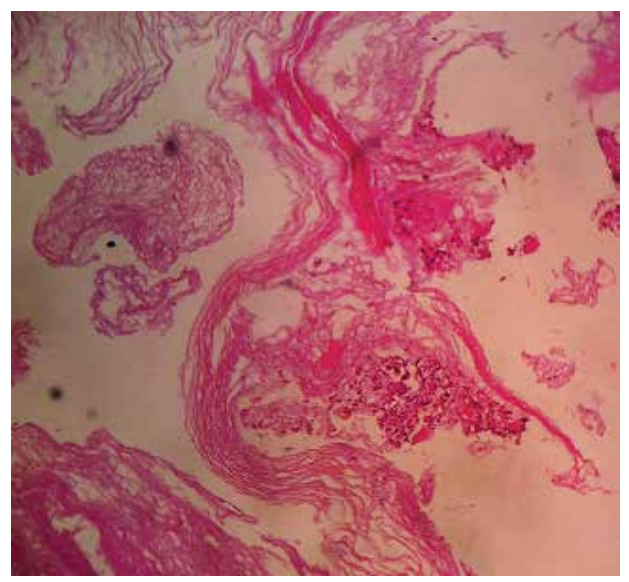

discharged from the hospital 5 days after operation. The result of pathological examination of the surgical specimen was reported as epidermoid tumor. The postoperative course was uneventful. At evaluation, one month later he had no neurological deficits and was leading a normal active life.

Slide shows clamps of laminated keratin admixed with areas of dystrophic calcification and few inflammatory cells.

\section{Discussion}

Intracranial epidermoid tumors are rare, usually benign, slow growing and can cause various symptoms. The rarity of these tumors has often led to delayed diagnosis. The onset of

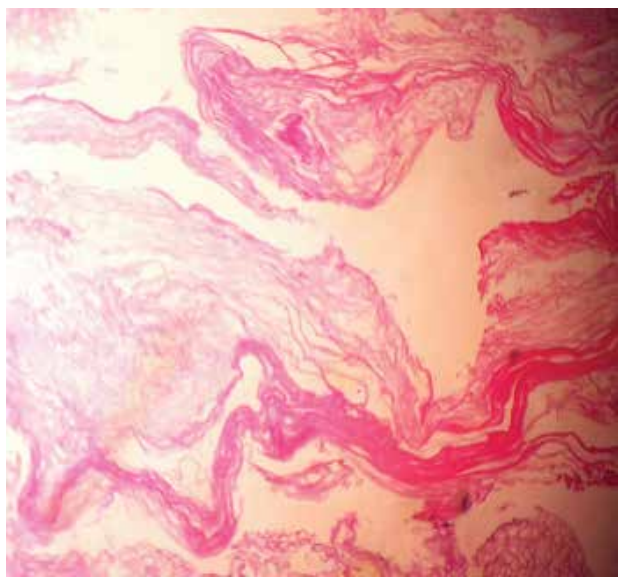

symptoms is usually in the third to fifth decade. 7,14 The parasellar and cerebellopontine angle regions are the most common sites and epidermoid tumors have been found in the fourth and lateral ventricles, cerebrum, 
cerebellum and brain stem. 3,7,13,14 They may also arise within petrous bone causing progressive facial paralysis and destruction of the bone. ${ }^{7}$ Congenital epidermoid tumors have also been reported over the anterior fontanelle. ${ }^{12}$ The occurrence of an epidermoid tumor in the interhemispheric region seems to be rare. Epidermoid tumors arise from a capsule of stratified squamous epithelium. They are usually entirely benign histologically and consist of desquamated epidermal cellular debris. These tumors vary greatly in size, but are consistently circumscribed. As in our case the interior is characteristically filled with soft white material, rich in cholesterol crystals. Progressive exfoliation of keratinous material towards the interior of the cyst produces the concentric layers of the contents and leads to slow expansion of the tumor. As mentioned above, these tumors are usually benign histologically, but will slowly recur if incompletely removed. Malignant change producing an invasive carcinoma has been reported. ${ }^{11}$ Goldman and Gandy ${ }^{6}$ documented a squamous cell carcinoma which developed in the bed of the lesion 33 years after surgical resection of a benign right lateral intraventricular epidermoid tumor. The most common single symptom is seizures and almost 50 per cent of patients with intracranial epidermoid tumors have repeated attacks of aseptic meningitis as a result of leakage of cyst contents into the CSF pathways. ${ }^{3,14}$ Evaluation of patients with intracranial tumor includes careful neurological and radiological examination. Epidermoid tumors are best diagnosed by CT and/or MRI. They often have a characteristic appearance on $\mathrm{CT}$ examination, presenting as hypo intense lesions with irregular margins with relatively little mass effect. As our case illustrates axial coronal and sagittal sections are helpful in delineating the extent of the tumor. They do not enhance after intravenous injection of a contrast agent. 5,8 which reflects the avascular nature of their contents. They only occasionally produce hydrocephalus. These lesions are found to have prolongation of both $\mathrm{Tl}$ and $\mathrm{T} 2$ relaxation times on MRI. ${ }^{8,10}$ The treatment of epidermoid tumor is surgical and the approach depends on the location of the tumor. Total excision can be considerably difficult as the capsule of these tumors is often remarkably adherent to vascular structures such as the carotid and basilar arteries as well as to cranial nerves and the brain stem substance. ${ }^{5}$ In such cases, complete removal is unwise and should be avoided. ${ }^{3}$ During removal of tumors, contamination of the surgical field and spillage of the cyst contents into the subarachnoid space should be avoided.

\section{References}

1. Alpers BJ.The cerebral epidermoids. Am J Surg.1939;43:55-58.

2. Alvord ED. Jr Growth rates of epidermoid tumors.Ann Surg. 1977;267-72.

3. Berger MS. Wilson CB. Epidermoid cysts of the posterior fossa. J Neurosurg. 1984;21: 1051-58.

4. Flemming JFR. Botterell EH. Cranial dermoid tumors.SurgGynecol Obstet. 1959;109:403-08

5. Gagliardi FM, Vagnozzi R, Caruso R, Delfini R.Epidermoids of the cerebellopontine angle (cpa): usefulness of CT scan. ActaNeurochir (Wien). 1980;54:271-81.

6. Goldinan SA. Gandy SE. Squamous cell carcinoma as a late complication of intracerebroventricular epidermoid cyst. J Neurosurg. 1987;66:618-20. 


\section{CASE REPORT}

7. Guidetti V. Gagliardi FM. Epidermoid and dermoid cysts: clinical evaluation and surgical results. J Neurosurg. 1977;47:12-18.

8. Ishikawa M. Kikuchi H. Asato R. Magnetic resonance imaging of the intracranial epidermoid. ActaNeurochir (Wien). 1989;101:108-11i.

9. Jefferson G, Sma1ley AA. Progressive facial palsy produced by intratemporalepidermoids. Laryngol. 1938;53:417-19

10. Kotman KE, Van Dalsem W, Bradley WG. MRI of intracranial epidermoid tumors. Radiology. 1985; p. 157: 71 11. Lewis AJ. Cooper PW, Kassel EE, Schwartz ML. Squamous cell carcinoma arising in a suprasellar- epidermoid cyst. J Neurosurg. -1983;59:538-41. 12. Martinez-Lage JF, Quinonez MA, Doza M, Duche A, Casas C, Costa RT: Congenital epidermoid cyst over the anterior fontanelle. Child's Nerv Syst.

1985;1:319-24.

13. Sweet WH: A review of dermoid, teratoid and teratomatous intracranial tumors. Dis Nerve Syst. 1940;1:228-38.

14. Ulrich J. Intracranial epidermoids. A study of their distribution and spread. J Neurosurg. 1964;21:1051-58. 15. Yasargil MG, Abernathey CD. Sanoglu AÇ. Microneurosurgical treatment of intracranial dermoid and epidermoid tumors. Neurosurgery. 1989;24:561-68. 